Journal of

Cancer Research and Therapeutic Oncology

\title{
Cellular and Molecular Characteristics of Established Neuroblastoma Cell Lines
}

Tohru Sugimoto ${ }^{1,2,3,4}$ Hiroshi Kuroda ${ }^{3,4,5}$ Sigeki Yagyu ${ }^{3}$, Takahiro Gotoh ${ }^{3}$, Shinya Osone ${ }^{3}$, Shinchi Tamura ${ }^{3,5}$, Tomoko Iehara ${ }^{3}$, Hajime Hosoi $^{3}$

\author{
${ }^{1}$ Shiga-ken Saiseikai Nursing School, Saiseikai Imperial Gift Foundation Inc, Ritto, Shiga, Japan \\ ${ }^{2}$ Saiseikai Shiga Hospital, Saiseikai Imperial Gift Foundation Inc, Ritto, Shiga, Japan \\ ${ }^{3}$ Department of Pediatrics, Kyoto Prefectual Univesity of Medicine, Kyoto, Japan \\ ${ }^{4}$ Department of Pediatrics, University of Miyazaki, Miyazaki, Japan \\ ${ }^{5}$ Department of Pediatrics, Kyoto City Hospital, Kyoto, Japan
}

${ }^{*}$ Corresponding author: Tohru Sugimoto, Shiga-ken Saiseikai Nursing School, Saiseikai Imperial Gift Foundation Inc, Ritto, Shiga, Shiga 520-3046, Japan. Tel:+81-77-553-7002, Fax:+81-77-553-7246; E-mail: tosugimo@koto.kpu.-m.ac.jp

Received Date: July 22, 2019 Accepted Date: September 02, 2019 Published Date: September 04, 2019

Citation: Tohru Sugimoto (2019) Cellular and Molecular Characteristics of Established Neuroblastoma Cell Lines. J Cancer Res Therap Oncol 7: 1-15.

\begin{abstract}
From 1984 to 2013, we established 29 childhood tumor cell lines and 16 neuroblastoma (NB) cell lines for cellular and molecular assays. NB diagnosis has been attempted with monoclonal antibodies against NB surface antigens (but not fetal neuroblasts), particularly with monoclonal antibody KP-NAC8. The multipotency of NB has been assessed during differentiation of NB cells into neurons, schwannian cells, smooth muscle cells. Regarding MYCN oncogene amplification (MNA) and tumorigenesis, the correlation between increased MNA and tumorigenesis in parental and subcloned NB cell lines, serum MYCN DNA levels, and MYCN DNA levels in primary tumors, cell lines, and serum in NB patients have been analyzed. Regarding neurotrophin and tyrosine kinase (TRK) family receptors, ciliary neurotrophic factor (CNTF) in NB cell lines have been analyzed, particularly TRK-A, TRK-B, and CNTF in NB cell lines. Differences in chemotherapeutic sensitivity between two NB cell lines derived from the same patient before and after chemotherapy have been discussed. Finally, improvement of NB prognosis with fenretinide, an apoptosis inducer in NB cell lines, and apoptotic induction using gefitinib (EGFR inhibitor) in NB cell lines have been discussed, along with potential novel therapeutic agents.
\end{abstract}

Keywords: Neuroblastoma, Cell line, Cellular characteristics, Molecular characteristics

Abbreviations: NB: neuroblastoma; MNA: MYCN oncogene amplification; NGF: nerve growth factor; BDNF: bone-derived neurotrophic factor; NT: neurotrophin; TRK: tyrosine kinase; CNTF: ciliary neurotrophic factor; IL: interleukin; MDR: multidrug resistance; FR: fenretinide; ROS: reactive oxygen species; RA: retinoic acid; BrdU: bromodeoxyuridine.

C2019 The Authors. Published by the JScholar under the terms of the Creative Commons Attribution License http://creativecommons.org/licenses/ by/3.0/, which permits unrestricted use, provided the original author and source are credited. 


\section{Introduction}

The characteristics of childhood malignancy are different from those of adult malignancies, with respect to embryogenesis, histological findings, physiological attributes, and their incidence. In leukemia, lymphoma, brain tumor, neuroblastoma (NB), retinoblastoma, Wilms tumor, hepatoblastoma, and soft-tissue sarcomas including rhabdomyosarcoma and Ewing's sarcoma, the formation of embryonic tumors and sarcomas is prominent. In the nationwide record of childhood malignancies in Japan, hematopoietic malignancies (including leukemia and lymphoma) and solid tumor malignancies account for approximately $40 \%$ and $50 \%$ of total malignancies, respectively.

During the last 30 years in our pediatric departments in Kyoto, Miyazaki, and the second Kyoto, Japan, our basic policies in our departments emphasize on "Harmony and hard work through healthy competition among colleagues," "Balancing clinical, educational, and research activities.

We previously attempted to establish cell lines derived from tumor tissue, bone marrow, or metastatic cells from peripheral blood and investigate their tumor-associated molecular characteristics, finally reporting their applicability in clinical studies.

From 1984 to 2013 we established 29 infant tumor cell lines, including $16 \mathrm{NB}$ cell lines [1] (Table 1), designated as either Kyoto Pediatrics (KP) or Miyazaki Pediatrics (MP), indicating the domestic products of these cell lines, along with the NB cell line (N). The applications of these NB cell lines in basic and clinical studies are discussed below to understand with respect to pediatric oncology.

Recent biological and clinical subtypes of NB based on age, INSS stage, MYCN amplification, DNA ploidy, 1p LOH, 17q gain, tyrosine kinase (TRK)- $A$ receptor expression, TRK- $B$ expression, and 5-year survival are described herein (Table 2).

\section{Establishment of $16 \mathrm{NB}$ cell lines from 12 patients}

Tumor samples for cell culture were obtained from biopsy, operative, or autopsy specimens and finely minced with scalpels and cultured. Mononuclear cell fractions from bone marrow or peripheral metastatic cells were prepared via Ficoll-Hypaque density gradient centrifugation. Cells were cultured in RPMI 1640 medium containing penicillin (100 U/ml), streptomycin $(100 \mu \mathrm{g} / \mathrm{ml})$ and $15 \%$ heat-inactivated fetal calf serum at $37^{\circ} \mathrm{C}$ and $5 \% \mathrm{CO} 2$. The media were changed every
3-4 d. Cell lines were considered to be successfully established on subculturing for more than 60 passages over a 2 -year period [1].

We first attempted to establish NB cell lines in 1983, when I have worked as a clinical research fellow (Cell Culture Laboratory, Molecular Biology, Roswell Park Memorial Institute, Buffalo, NY) under Professor Jun Minowada (one famous leukemia biologist, and one of the RPMI 1640 medium developers). Our research colleague advised that "At least two tumor cell lines had to been established when you are able to be eligible for a researcher". The final goal of establishing tumor cell lines is to unravel novel diagnostic or therapeutic methods for cancer.

The NB cell line is one of the most traditional human cell lines, and first NB cell lines NB-1 [2] and SK-N-SH [3] were established in 1973. NB-1 was established by Dr. Shinsaku Imashuku at our institute in the Departments of Pediatrics and Pathology and catecholamine metabolism was assessed in this NB cell line [2]. SK-N-SH [3] was established by Dr. June L Biedler at the Memorial Sloan-Kettering Cancer Center and its morphology, growth characteristics, tumorigenicity, and cytogenetics were assessed. Since then, more than $110 \mathrm{NB}$ cell lines have been reported [4]; however, certain additional NB cell lines also exist. In this review, the cellular and molecular aspects of these established NB cell lines are discussed.

\section{Monoclonal antibodies against NB cell surface anti- gens}

\section{(1) Diagnosis of NB tumors with a panel of monoclonal an- tibodies}

Many surface antigens are expressed on tumor cells, and monoclonal antibodies against tumor cell surface antigens have been developed; however, NB-specific antigens have not been reported. Although NB has not been diagnosed using a single monoclonal antibody, a panel of monoclonal antibodies enabled us to detect NB cells. 
Table 1 Sixteen established neuroblastoma cell lines from 12 patients

\begin{tabular}{|c|c|c|c|c|c|c|c|c|c|c|}
\hline No & Cell line & Patient & $\begin{array}{l}\text { Primary } \\
\text { tumor }\end{array}$ & Stage & Metastasis & Sample & Therapy & $\begin{array}{c}\text { MYCN } \\
\text { amp }\end{array}$ & $\begin{array}{l}\text { Out- } \\
\text { come }\end{array}$ & References \\
\hline 1 & $\begin{array}{l}\text { KP-N- } \\
\text { RTBM }\end{array}$ & $\begin{array}{c}1 \text { y } 2 \\
\mathrm{~m}\end{array}$ & Adr gl & 4 & BM, Bone & $\mathrm{BM}$ & Before & 50 & Dead & $\begin{array}{l}8,12-14,19 \\
29\end{array}$ \\
\hline 2 & $\begin{array}{l}\text { KP-N- } \\
\text { RTLN }\end{array}$ & $\begin{array}{c}1 \mathrm{y} 2 \\
\mathrm{~m}\end{array}$ & Adr gl & 4 & $\begin{array}{c}\text { BM, Bone, } \\
\text { LN }\end{array}$ & $\mathrm{LN}$ & Before & 50 & Dead & $8,12,15,28$ \\
\hline 3 & RT-BMV & $\begin{array}{c}1 \mathrm{y} 2 \\
\mathrm{~m}\end{array}$ & Adr gl & 4 & BM, Bone & $\mathrm{BM}$ & Before & 100 & Dead & 22 \\
\hline 4 & $\begin{array}{l}\text { KP-N-SI- } \\
\text { LA }\end{array}$ & $5 \mathrm{y}$ & Adr gl & 4 & LN · Bone & LN & Autopsy & 1 & Dead & $14,16-19,28$ \\
\hline 5 & $\begin{array}{l}\text { KP-N-SI- } \\
\text { FA }\end{array}$ & $5 y$ & Adr gl & 4 & $\mathrm{LN} \cdot$ Bone & Bone & Autopsy & 1 & Dead & $\begin{array}{l}19,29,32, \\
34\end{array}$ \\
\hline 6 & KP-N-YN & $2 y$ & Adr gl & 3 & $\mathrm{LN}$ & $\begin{array}{l}\text { Delayed } \\
\text { primary }\end{array}$ & During & 100 & Dead & 17,19 \\
\hline 7 & KP-N-AY & $\begin{array}{c}2 \mathrm{y}^{6} \\
\mathrm{~m}\end{array}$ & Adr gl & 4 & $\mathrm{LN} \cdot \mathrm{BM}$ & $\mathrm{BM}$ & Before & 50 & Dead & 30,31 \\
\hline 8 & $\begin{array}{l}\text { KP-N- } \\
\text { AYR }\end{array}$ & $\begin{array}{c}2 \text { y } 6 \\
\mathrm{~m}\end{array}$ & Adr gl & 4 & $\mathrm{LN} \cdot \mathrm{BM}$ & $\mathrm{BM}$ & During & 50 & Dead & 30,31 \\
\hline 9 & MP-N-MS & $\begin{array}{c}1 \text { y } 6 \\
\mathrm{~m}\end{array}$ & Adr gl & 4 & $\mathrm{BM}$ & $\mathrm{BM}$ & Before & 50 & Dead & 19 \\
\hline 10 & KP-N-YS & $4 y$ & Adr gl & 4 & $\mathrm{BM}$ & $\mathrm{BM}$ & Before & 10 & Dead & 19 \\
\hline 11 & MP-N-TS & $\begin{array}{c}2 \text { y } 8 \\
\mathrm{~m}\end{array}$ & Adr gl & 4 & $\begin{array}{c}\text { Bone - Gin- } \\
\text { giva }\end{array}$ & Primary & Before & 1 & Dead & $27,29,33$ \\
\hline 12 & KP-N-HN & $4 y$ & Adr gl & 4 & $\mathrm{BM}$ & $\mathrm{BM} \cdot$ & During & 1 & Dead & 29 \\
\hline 13 & KP-N-NY & $5 y$ & Adr gl & 4 & $\mathrm{BM}$ & $\begin{array}{l}\text { Delayed } \\
\text { primary }\end{array}$ & During & 1 & Dead & 29 \\
\hline 14 & KP-N-SK & $\begin{array}{c}2 \mathrm{y}^{2} \\
\mathrm{~m}\end{array}$ & Adr gl & 4 & Bone $\cdot \mathrm{BM}$ & $\mathrm{BM}$ & Before & 45 & Dead & Unpublished \\
\hline 15 & $\begin{array}{l}\text { KP-N-Yu- } \\
\text { No }\end{array}$ & $\begin{array}{c}1 \text { y } 5 \\
\mathrm{~m}\end{array}$ & Retro & 4 & $\mathrm{LN} \cdot$ & Primary & Before & 10 & Dead & Unpublished \\
\hline 16 & KP-N-TK & $\begin{array}{c}1 \text { y } 1 \\
\text { m }\end{array}$ & Adr gl & 4 & BM - Bone & Primary & Before & 20 & Alive & $1,32,33$ \\
\hline
\end{tabular}


Table 2 Biological and clinical subtypes of neuroblastoma (Brodeur GM. 2003)

\begin{tabular}{|c|c|c|c|}
\hline Feature & Type 1 & Type 2A & Type 3B \\
\hline Age & Usually< $1 \mathrm{yr}$ & Usually $>1$ yr & Usually 1-5 yr \\
\hline INSS Stage & Usually $1,2,4 \mathrm{~S}$ & Usually 3,4 & Usually 3, 4 \\
\hline MYCN & Normal & Normal & Amplified \\
\hline DNA ploidy & Hyperdiploid/ near triploid & Near diploid/near tetraploid & Near diploid/near tetraploid \\
\hline 1p LOH & Rare & Uncommon & Common \\
\hline 17q gain & Rare & Common & Common \\
\hline TRK- $A$ exp. & High & Low or absent & Low or absent \\
\hline TRK-B exp. & Truncated & Low or absent & High (full length) \\
\hline 5-yr survival & $95 \%$ & $40-50 \%$ & $25 \%$ \\
\hline
\end{tabular}

Cell lines KP-N-RTBM and right-axillary lymph node KP-N-RTLN from a 1-year-2-month-old patient with a stage 4 bone marrow malignancy were established (Figure 1). Subsequently, six cloned cell lines (RT-BM series) and 12 cloned cell lines (RT-LN series) were established from each parental NB cell line. A panel of monoclonal antibodies was used, and four key monoclonal antibodies, including CD24 (BA-1), UJ-127-11, PI153/3 (KP-NAC10), and KP-NAC8 (described below), were identical to bone marrow tumor cells in an RT patient, KP-NRT parent cell lines, and KP-N-RT cloned cell lines (Table 3) [58].

Thus, NB cell surface antigens are stably expressed during culturing for at least 2 years, and the analysis of NB cell surface antigens was rapid and accurately detected bone marrow tumor infiltrates (required duration, $2 \mathrm{~h}$ ) and NB cell lines.

\section{(2) Cell surface antigen present on NB cells but not fetal neu-} roblasts

Monoclonal antibodies (KP-NAC2, KP-NAC8, KPNAC9, and KP-NAC10) against a KP-N-RT NB cell line have been developed and commercially purchased by Seikagaku Corporation, Tokyo, Japan (http://www.seikagaku.co.jp/english/index.html). KP-NAC2 potentially binds to neuroectodermal-related antigens; KP-NAC9, Thy-1 antigens; KP-NAC10, PI 153/3 common ALL antigens [9]. Interestingly, the specificity of KPNAC8 for NB cells but not fetal neuroblasts provided further information regarding biological differences among NB, NB in situ, and fetal neuroblasts [10] (Figure 2).

Thirty years have elapsed since the development of KPNAC8, and the purification methods for antibody-defined antigens have revealed significant progress; however, the epitope recognized by the antibody remains undefined.

\section{Multipotency of NB cells}

Differentiation or maturation of NB cells has been assessed in vivo during the clinical course of NB. NB cells have been derived from tumors originating from the neural crest, and neural crest cells differentiate or mature into peripheral nerve cells, schwannian cells, melanocytes, or smooth muscle cells (Figure. 3) $[11]$.

\section{(1) Differentiation of NB cells into neurons}

$\mathrm{NB}$ cells have been cultured in vitro with dbcAMP, prostaglandin $\mathrm{E}_{2}$, nerve growth factor (NGF), and retinoic acid (RA). A new synthetic polyprenoic acid (E5166), with similar properties to those of RA and lesser toxicity than synthetic RA, has been used previously (Eisai Co., Ltd., Tokyo, Japan; https:// www.eisai.com/index.html), and E5166-mediated neuronal differentiation has been assessed in vitro and may help eradicate residual tumor cells (Figure. 4) [12,13]. Two NB cell lines (KP-NSIFA and KP-N-RT) have been induced to undergo neuronal differentiation via interferon-gamma and HLA-DR and HLA-DP; however, HLA-DQ-mediated induction has not been reported, demonstrating the biological independent among HLA-DR, -DP, and -DQ antigens [14]. 
Table 3 Analysis of surface membrane antigens in bone marrow tumor cells and parental and cloned neuroblastoma cell lines

\begin{tabular}{|c|c|c|c|c|c|}
\hline \multirow{2}{*}{$\begin{array}{c}\text { Monoclonal } \\
\text { antibody }\end{array}$} & \multirow{2}{*}{$\begin{array}{l}\text { Bone marrow } \\
\text { tumor cells }\end{array}$} & \multicolumn{2}{|c|}{ Parental cell lines } & \multicolumn{2}{|c|}{ Cloned cell lines } \\
\hline & & RT-BM & RT-LN & RT-BM1 6 & RT-LN1 12 \\
\hline$\underline{\text { CD24 (BA-1 }}$ & & & & & \\
\hline CD9 (BA-2) & & & & & \\
\hline CD10 (J-5) & & & & & \\
\hline HLA-DR & & & & & \\
\hline CD56 (UJ-13. & & & & & \\
\hline UJ-127-11 & & & & & \\
\hline anti-Thy-1 (KP-N & & & & & \\
\hline HSAN1.2 & & & & & \\
\hline 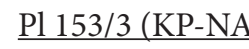 & & & & & \\
\hline$\underline{\mathrm{KP}-\mathrm{NAC} 8}$ & Not tested & & & & \\
\hline
\end{tabular}

Positive

Onegative

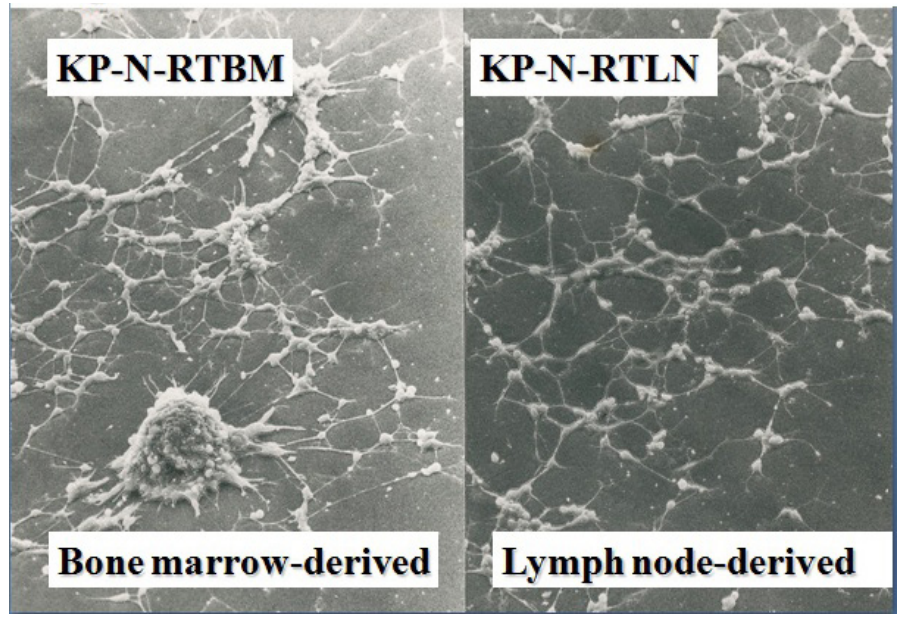

Figure.1 Establishment of the KP-N-RT NB cell line. KP-NRTBM cells were derived from the bone marrow; KP-NRTLN cells, lymph nodes.
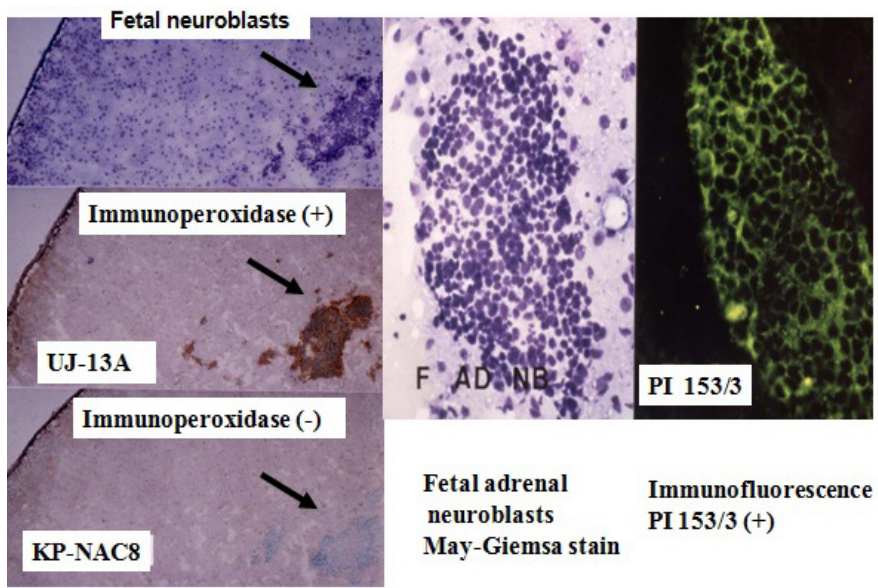

Figure. 2 Cell surface membrane antigen on neuroblastoma (NB) cells, but not on fetal neuroblasts, on using the monoclonal antibody KP-NAC8.
Under line= Key antibody

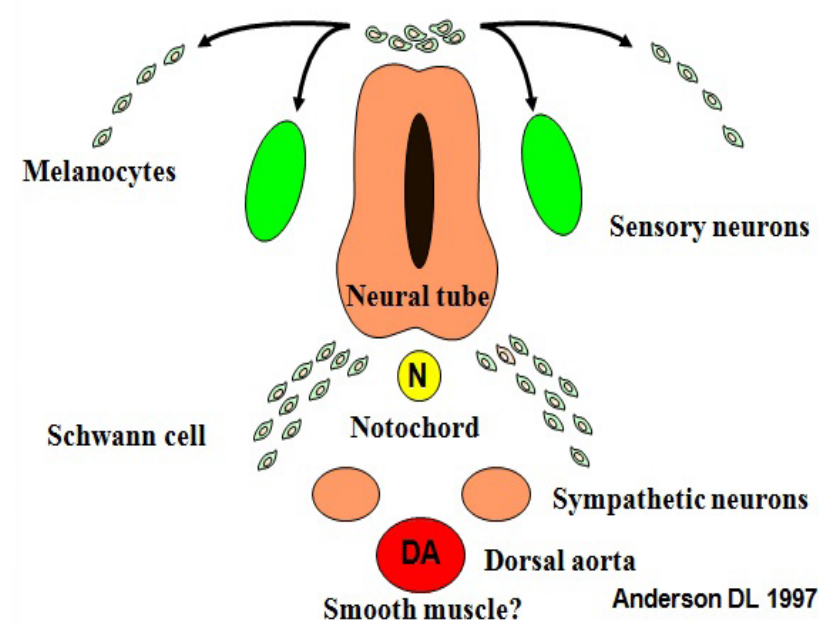

Figure. 3 Derivatives of the neural crest in the trunk.

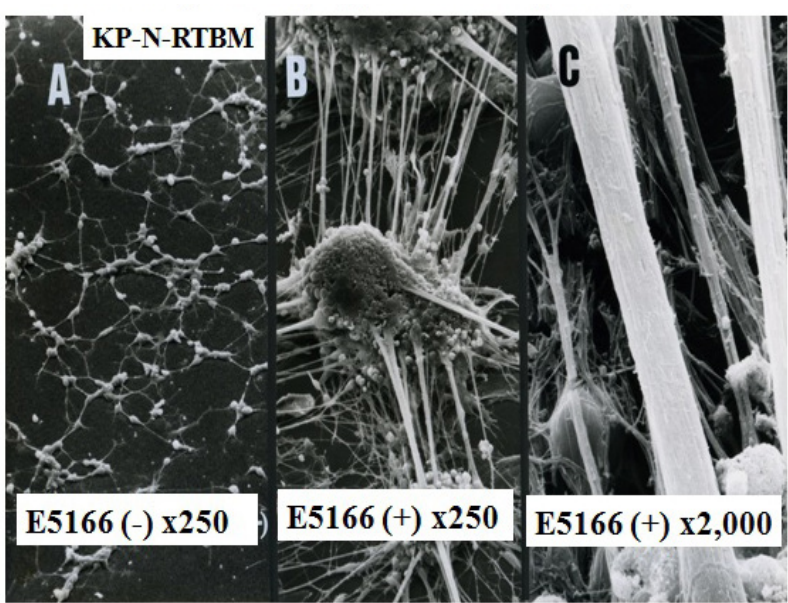

Figure. 4 Neuronal Differentiation of KP-N-RT NB cells induced with synthetic polyprenoic acid (E5166). 
(2) Differentiation of NB cells into schwannian cells

Differentiation of NB cells into schwannian cells is based on pathological evidence that S100-rich tumors of NB patients have a better prognosis. Upon treatment with bromodeoxyuridine (BrdU), flat epithelial cells increased and 2'3'-cyclinc nuclotide-3'-phosphodiesterase activity was significantly elevated, indicating schwannian differentiation upon BrdU treatment [15].

$\mathrm{N}$-myc downregulation and c-src upregulation have been reported during neuronal differentiation with E5166, while these proteins were markedly downregulated during schwannian differentiation upon BrdU treatment, indicating that $\mathrm{N}$-myc and c-src expression is regulated independently during bipolar differentiation of NB cells [16]. Schwannian cells are considered to be derived from NB probably upon BrdU treatment in vitro or the conversion of vascular endothelial cells to schwannian cells in tumor tissues. This origin warrants further evaluation.



Figure. $5 \mathrm{~N}$ - and S-cells in NB cell lines. During culturing, both spindle-shaped neurons and flat substrate-adhesive (S) cells were observed.

\section{(3) Differentiation of NB into smooth muscle cells}

Differentiation of neural crest cells into ectomesenchymal cells has been extensively studied using the chimeric quail-chick embryo model. The cephalic neural crest gave rise to bone and cartilage of the head and facial region and connective tissues including smooth muscle tissue of the wall of large arteries derived from branchial arches.

In some NB cell lines, neuronal (N)-cells, and substrate-adhesive (S)-cells showing epithelial-like characteristics were observed during the cell culture period (Figure. 5). In S-cells, alpha-smooth muscle actin and/or desmin (intermedi- ate filaments in smooth muscle cells) were expressed [17-19]. Furthermore, six NB cell lines, MP-N-MS, KP-N-YS, KP-NSI9s, KP-N-YN1s, KCN11s, and KP-N-YS2s, expressed smooth muscle-specific cytoskeletal proteins including alpha-smooth muscle actin and basic-calponin (Figure 6). Consequently, only one NB cell line, MP-N-MS, derived from a patient MS, expressed basic-calponin, SM1, and SM2 isoforms (Figure. 6-7 in MP-N-MS). MP-N-MS is an NB cell line with SM1 and SM2 isoforms at protein and mRNA levels (Figure. 8). These results indicate that MP-N-MS has the most mature smooth-muscle phenotype among the S-cell NB cell lines. Thus, our observations first indicated the potential differentiation pathway of NB into smooth muscle cells in the human system.

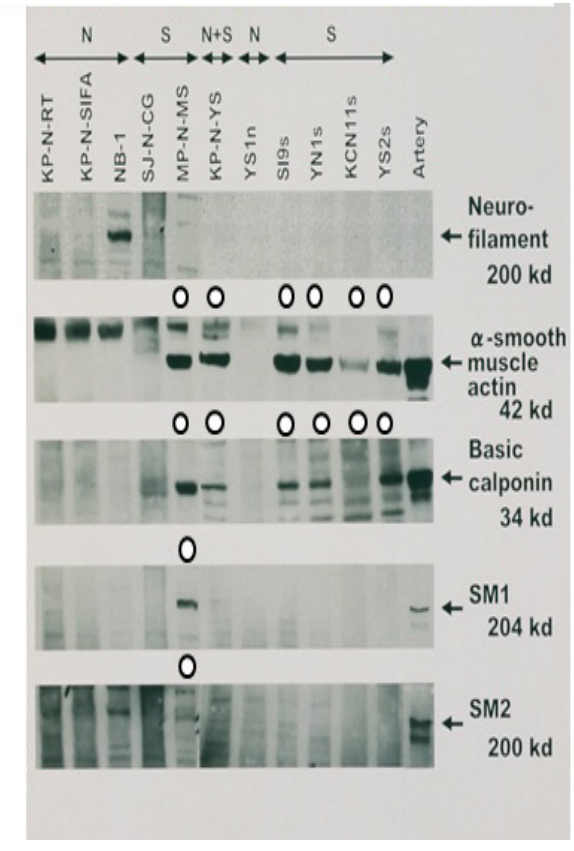

Figure. 6 Cytoskeletal proteins of S-cells in NB cell lines (Western blot).


Figure. 7 Cytoskeletal proteins in the MP-N-MS NB cell line. 

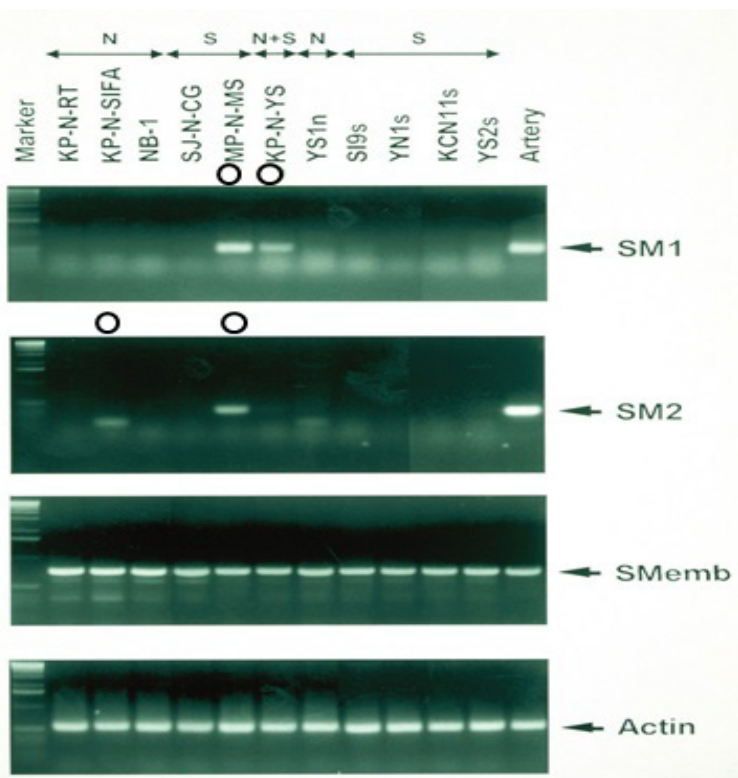

Figure. 8 Myosin heavy chain in NB cell lines. MYCN oncogene amplification (MNA) and tumorigenesis

MYCN (N-myc), a cellular oncogene homologous to the c-myc oncogene, was identified in NB cell lines and advanced NB tumor tissues [20]. Previous studies have reported that MNA in primary NB tumors is highly correlated with rapid disease progression and poor prognosis. MYCN oncogene has been considered in the stratification curve for therapies and is the first and most well-known oncogene [21]. MNA, associated with tumor growth and cell division, has been reported in $4 \%$ of cases of stage 1 and 2 disease (with early-stage), $8 \%$ of cases of stage $4 \mathrm{~S}$ disease (less than one year age with liver, skin, and bone marrow metastases), and 30\% of cases of stage 3 and 4 disease.

(1) Correlation between increased MNA and tumorigenesis in parental and subcloned NB cell lines

The RT-BM-1 cell line cloned from the KP-N-RT parental cell line displayed spindle-like morphology with neural processes and contained 50 copies of MNA, as revealed through Northern blot analysis, whereas the RT-BMV-C6 subline had a flat morphology and harbored more copies of MNA (100 copies), originating from KP-N-RT cells [22] (Figure. 9). The RT-BM-1 subline and parental clone RT-BMV-C6 were inoculated at the right or left flank areas of five nude mice. No tumor growth was observed in the RT-BM-1 parental cell line inoculated in the right flank; however, inoculation of all RT-BMV-C6 sublines resulted in tumor growth in the left flank. Thus, our previous study shows the association between MNA and tumorigenesis in mice in vivo (Figure.10) [22].

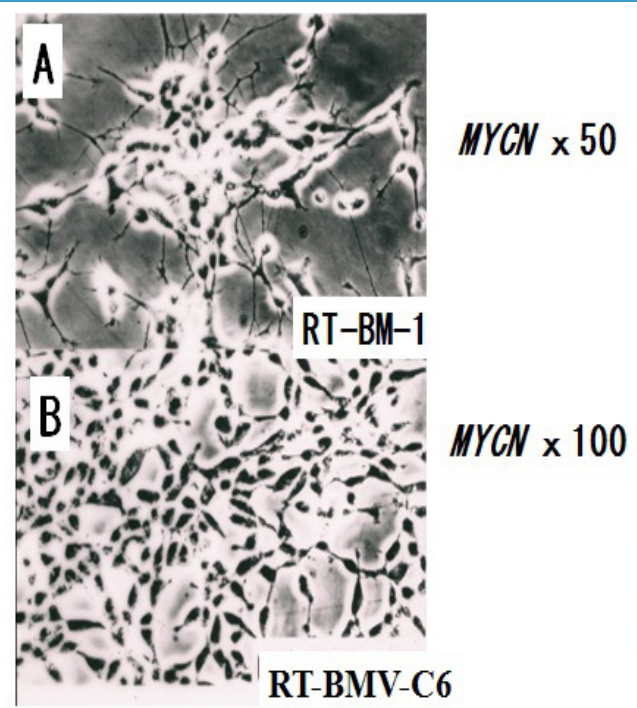

Figure. 9 Subline RT-BM-1 and clone KT-BMV-C6 derived from the KP-N-RT NB cell line.

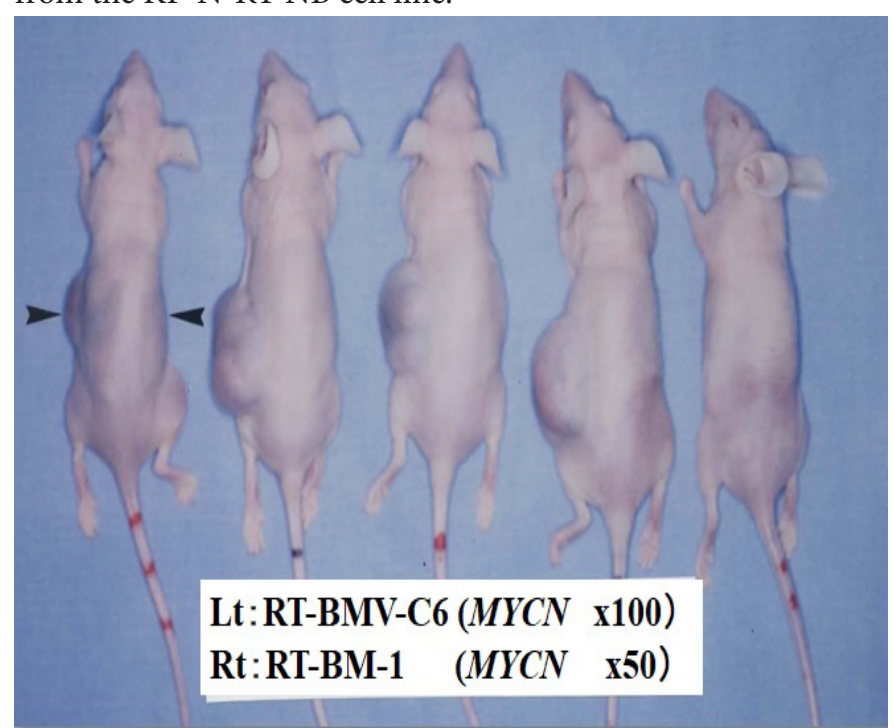

Figure. 10 Inoculation of the RT-BMV-C6 (left flank) subline and the RT-BM-1 (right flank) parental cell line originating from the KP-N-RT NB cell line.

\section{(2) Determination of serum MYCN DNA levels}

MNA is the most important indicator of a poor prognosis on NB based on tumor-associated genes. MNA was previously determined via Southern blotting (required duration, $7 \mathrm{~d}$ ), fluorescence in situ hybridization (for 2-3 days), and real-time PCR analysis, for a shorter duration (4 h) and for accuracy. We previously developed a method for determining MNA using cell-free DNA fragment released from NB cells into the blood of patients (Figure. 11). 
Using DNA-based real-time quantitative PCR, we simultaneously quantified MYCN (2q24) and a reference gene, NAGK (2p12) and evaluated the copy number of MYCN as an $M Y C Y / N A G K(M / N)$ ratio for $87 \mathrm{NB}$ patients, whose MYCN status was determined via Southern blotting [23]. In addition, the stability of serum DNA-based $M Y C N$ as an M/N ratio was examined using cell supernatant fluid from our NB cell lines (KP$\mathrm{N}-\mathrm{TK}$ and KP-N-RT), and we found that they were stable at 25, $4,-30$, and $-80^{\circ} \mathrm{C}$ for $7 \mathrm{~d}$ or freeze-thaw cycles (Figure. 12). Of these patients, MNA was reported in 17 and not reported in 70 patients. The serum $\mathrm{M} / \mathrm{N}$ ratio in the MNA group was significantly greater than that in the non-MNA group. The sensitivity and specificity of the serum $\mathrm{M} / \mathrm{N}$ ratio as a diagnostic parameter were $100 \%$ when the serum $\mathrm{M} / \mathrm{N}$ ratio cutoff was set at 10.0 (Figure. 13). Determination of the serum $\mathrm{M} / \mathrm{N}$ ratio is hence a seemingly promising method for accurately assessing the MYCN status in NB [23]; furthermore, it serves as a surrogate biomarker for NB based on serum MNA [24].

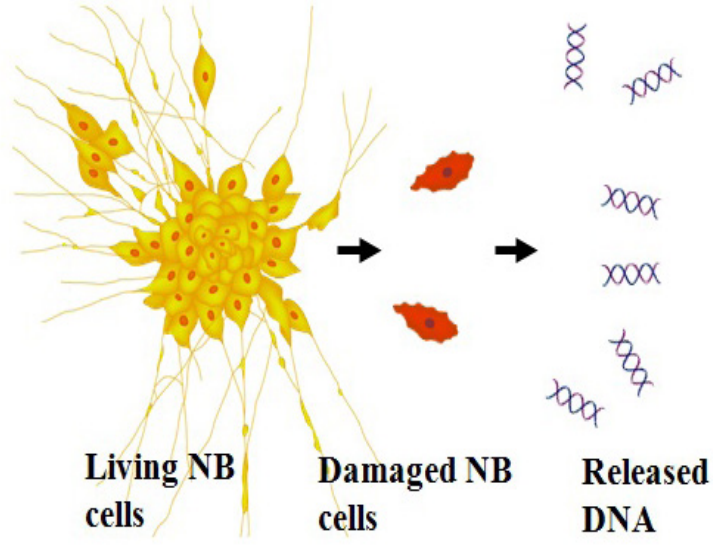

Figure. 11 Serum MYCN DNA predominantly originating from neuroblastoma-released DNA.

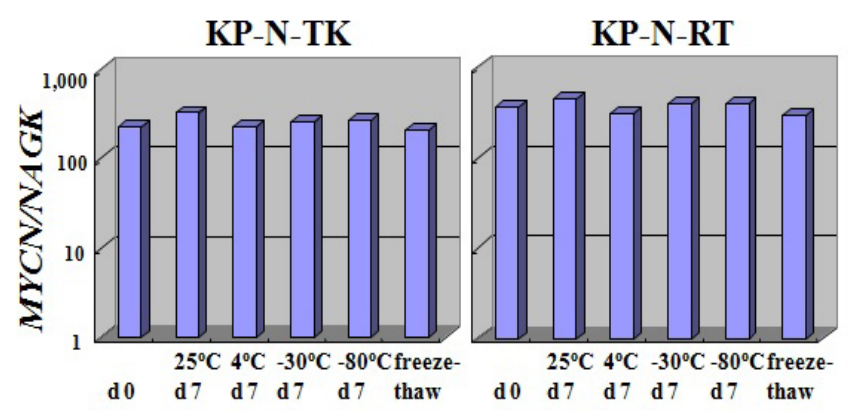

Figure. 12 Stability of culture supernatant fluids in MYCN-amplified NB.

\section{Serum $M Y C N / N A G K$ ratio: \\ MYCN Status median range \\ Non-Ampli (n=70) $0.870 .25-4.6$ \\ Ampli $\quad(n=17)$ 199.3 7.1-901.6 \\ (p<0.001: Mann-Whitney U test)}

2. Cutoff value of $\mathbf{1 0 . 0}$ :

When we empirically selected a cut off value of 10 , which was in the middle of the two groups,

Specificity, Sensitivity

Positive predictive value

Negative predictive value

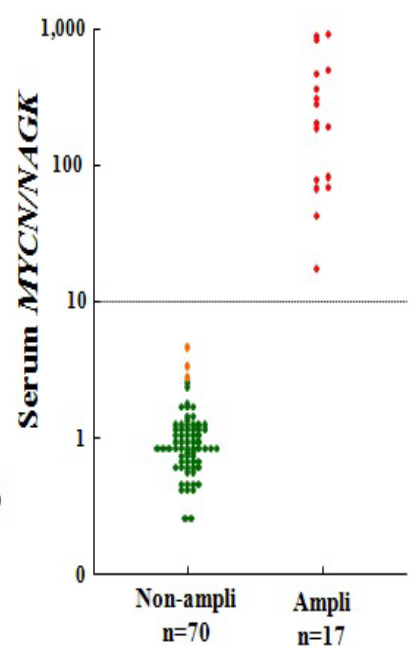

Figure. 13 The serum MYCN/NAGK ratio in the MYCN-amplified group was significantly higher than that in the non-amplified groups.

(3) MYCN DNA levels in the primary tumor, NB cell line, and serum in NB patients

MYCN DNA levels, expressed as $\mathrm{M} / \mathrm{N}$ ratios, in the primary tumor and patient serum at diagnosis were very simi$\operatorname{lar}$ (347 and 319, respectively). The M/N ratio in the KP-N-TK cell line at passage 70 (931) was 2.7-fold that of the primary tumor (347), indicating the selection of an $M Y C N$-amplified clone during culturing. In patient TK, the serum MYNC level was 319 at diagnosis in March 1992, which decreased to 0.6 on September 1993 after 5 months of chemotherapy, and has consistently remained low for the last 18 years (Figure. 14) [1]. Serum levels of MYCN DNA in patient TK (which decreased to 0.6) consequently indicated the eradication of residual NB cells and the chemosensitivity of TK tumor cells owing to chemotherapy with PBSCT. Thus, this is the first report of long-term (18-year) accurate monitoring of the serum $\mathrm{M} / \mathrm{N}$ ratio in $M Y C N$ DNA levels.

\section{Neurotrophin, TRK family receptors, and CNTF in NB cell lines}

Neurotrophins, including NGF, brain-derived neurotrophic factor (BDNF), neurotrophin (NT)-3, and NT-4/5 play important roles in the development of the peripheral and central nervous systems. These neurotrophins have several functions in cell survival, differentiation, and proliferation, apoptosis, and guidance of the outgrowth of neuronal processes. Neurotrophin function is mediated by the TRK receptor family (TRK-A, TRK-B, and TRK-C) (Figure 15). TRK-A upregulation in NB tumors is correlated with a favorable prognosis [25]; TRK-B upregulation, poor prognosis [26]. Therefore, the rare MP-N-TS cell lines, constitutively expressing both TRK-A and TRK-B receptors, have been utilized (Figure 16) [27] 


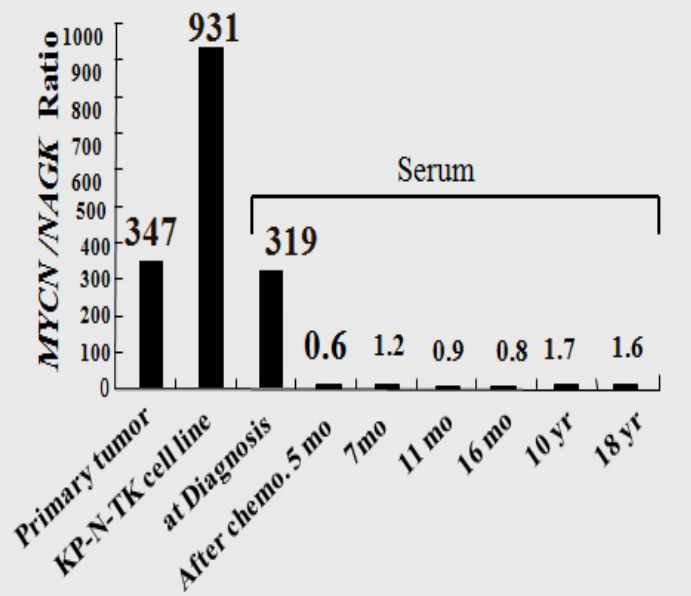

Figure. 14 MYCN DNA levels in tumors of patient TK, the KP$\mathrm{N}$-TK cell line, and patient serum before and after chemotherapy, as determined via quantitative PCR analysis.

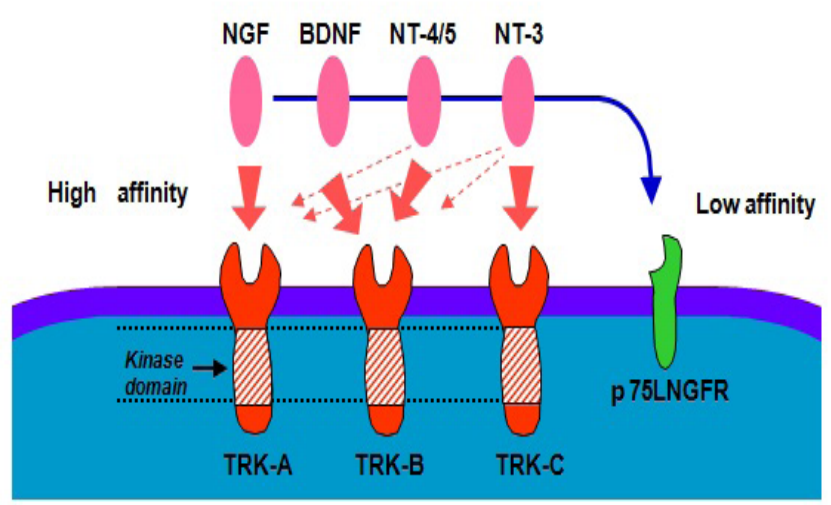

Figure. 15 Association between tyrosine kinase family receptors with ligands.
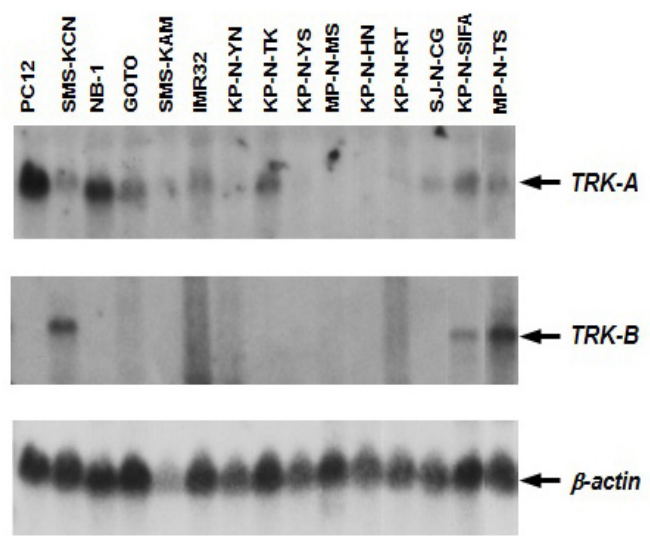

Figure. 16 TRK- $A$ and TRK-B expression in a panel of $14 \mathrm{NB}$ cell lines.

\section{(1) TRK-A receptor in NB cell lines}

We recently analyzed TRK-A expression in 14 of our NB cell lines. TRK-A was expressed in eight (57\%) of these NB cell lines, as revealed through Northern blotting (Figure. 16) and in 11 (65\%) of $17 \mathrm{NB}$ cell lines, as revealed through RT-PCR analysis, indicating an unexpected upregulation of TRK-A [27, 28]. Furthermore, tyrosine phosphorylation of the TRK-A receptor (Figure. 17), Shc, ERK-1, ERK-2, and PLC-r1 proteins via NGF and expression of c-fos, an immediate-early gene, was induced in the MP-N-TS cell line [27]. However, in NB cell lines, tyrosine phosphorylation of TRK-A receptors, Shc, ERK-1, ERK-2, or PLC-r1 via NGF was blocked in various stages during signal transduction (data not shown).

\section{(2) TRK-B receptor in NB cell lines}

TRK-B is the receptor of BDNF and NT-4/5 neurotrophins, and TRK-B expression is associated with a poor prognosis in NB tumors [26]. Therefore, TRK-B signal transduction and the effect of BDNF and NT-4/5 neurotrophins on proliferation in NB cells has been investigated (Figure. 18). Both TRK-A and TRK-B receptors are rarely co-expressed in an NB cell line, and only 3 of our 14 NB cell lines display dural expression patterns (Figure.16).

Treatment with NGF, BDNF, and NT-4/5 potentially induces morphological differentiation. The TRK-A receptor was phosphorylated by NGF at its tyrosine residue, whereas TRK-B receptor was phosphorylated by BDNF and NT-4/5 on its tyrosine residue (Figure. 17). With these four neurotrophins, signal transduction via phosphorylated Shc, ERK-1, and ERK-2, was activated through PLC-r1, and finally c-fos, an immediate-early gene was induced. Morphological differentiation of neurite outgrowth was induced by neurotrophins. NGF did not have a significant effect on cell proliferation, whereas BDNF and NT$4 / 5$ increased the numbers of viable cells (Figure. 18) [27]. This MP-N-TS cell line was useful to elucidate the diverse TRK family receptor-mediated signaling pathways, including neuronal differentiation, proliferation, survival, and apoptosis in NB cells [27]. 


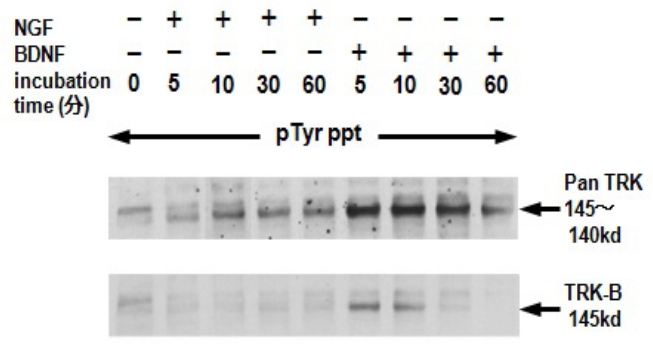

Figure. 17 Time-course of tyrosine phosphorylation of panTRK and TRK-B receptor proteins with nerve growth factor and bone-derived neurotrophic factor in MP-N-TS NB cells.

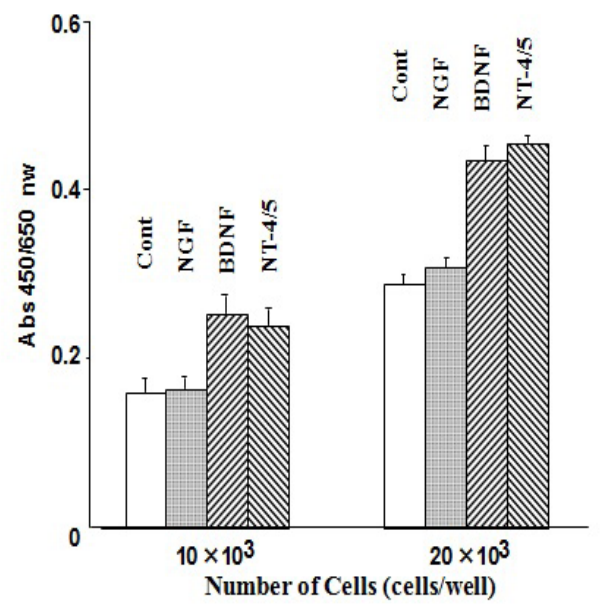

Figure. 18 Effect of nerve growth factor, bone-derived neurotrophic factor, and neurotrophin- $4 / 5$ on cell viability in MP-NTS NB cells.

\section{(3) CNTF expression in NB cell lines}

CNTF is not a member of the TRK family but rather the interleukin-6 (IL-6) cytokine family and influences the survival and differentiation of neurons. Therefore, the effect of CNTF on NB cells was examined (Figure. 19). For signal transduction, CNTF requires a receptor complex, comprising the IL-6 signal transducing molecule gp130, leukemia inhibitory factor receptor-beta, and CNTFR-alpha. Two major independent pathways (the Jak-STAT pathway and the RasMAPK pathway) are involved in cell signaling. The signal of the IL- 6 family is primarily transduced to the Jak-STAT pathway through gp130; however, this has not been assessed in NB cell lines. We examined the signaling pathway of CNTF in 11 NB cell lines. Northern blot analysis revealed that three of the 11 cell lines (KP-N-HN, MP-N-TS, and KP-N-NY) expressed c-fos mRNA after CNTF stimulation (Figure. 19). Tyrosine phosphorylation of gp130, Jak1, and STAT3 was observed after CNTF stimulation in these three cell lines (Figure. 20). Furthermore, tyrosine phosphorylation of ERK1 was observed in these cell lines.

These results provide the initial evidence that CNTF signaling is conserved in some of the NB cell lines, suggesting that not only the Jak-STAT pathway but also the MAPK pathway are activated by CNTF through gp130 in NB cell lines [29].

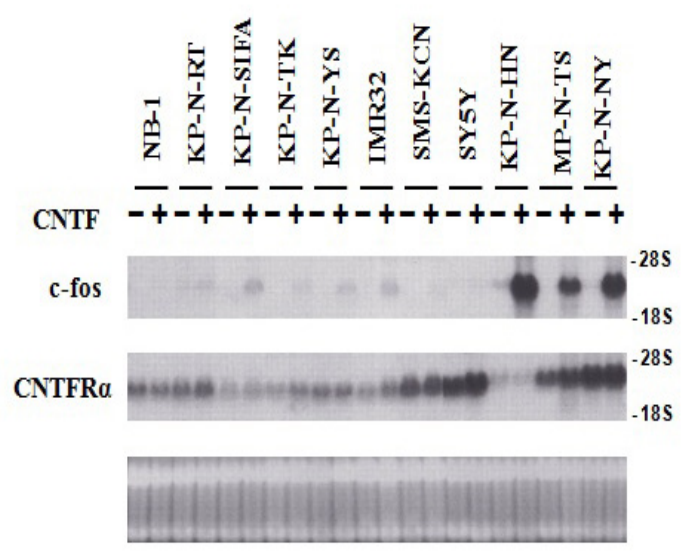

Figure. 19 Induction of c-fos expression by ciliary neurotrophic factor in $11 \mathrm{NB}$ cell lines.

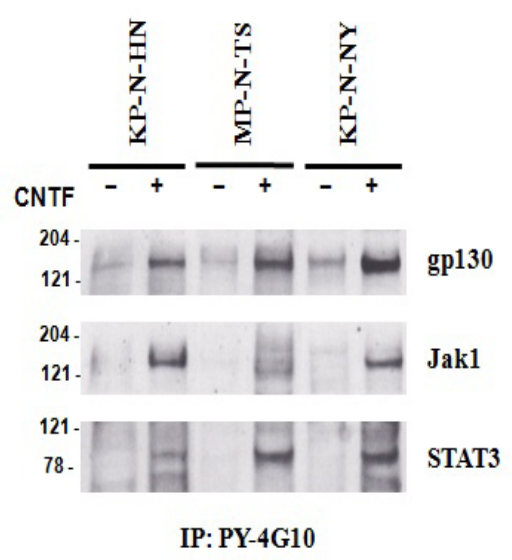

Figure. 20 Tyrosine phosphorylation of gp130 Jak1 and STAT3 in KP-N-HN, MP-N-TS, and KP-N-NY NB cells. 
Differences in drug sensitivity in two NB cell lines established from the same patient before and after chemotherapy

The establishment of two NB cell lines from the same patient before (KP-N-AY) and after chemotherapy (KP-N-AYR) is quite rare. KP-N-AY was established from bone-marrow metastases of a 2 y-6-mo-old patient with stage $4 \mathrm{NB}$ in October 1984; KP-N-AYR, December 1985.

Chemotherapeutic resistance is a major impediment for treating advanced NB. Compared with the KP-N-AY cell line, the KP-N-AYR line had decreased N-myc amplification but increased $\mathrm{N}$-myc expression. A clonogenic assay for in vitro sensitivity revealed that the KP-N-AYR cell line is 3.0-fold resistant to adriamycin and 2.7-fold resistant to cis-platinum compared to the KP-N-AY cell line. These findings suggest that the development of clinical chemotherapeutic resistance is potentially associated with enhanced glutathione-S-transferase-pi activity but not with MDR1 gene expression [30].

However, a gene mapped to chromosome 10q23, PTEN/ $M M A C 1$, was identified as a tumor suppressor gene inhibiting cell survival and cell proliferation. Thus, functional inactivation of the PTEN/MMAC1 mutation was observed in the KP-N-AYR cell line, but not in the KP-N-AY cell line, thus probably resulting in tumor recurrence in the patient from these two cell lines [31].

\section{NB and apoptosis}

$\mathrm{NB}$ at stage $4 \mathrm{~S}$ is limited to infants aged less than 1 year and is a localized primary tumor (as in stage $1,2 \mathrm{~A}$, or $2 \mathrm{~B}$ ) with metastasis limited to the skin, liver, and/or bone marrow. Stage $4 \mathrm{~S}$ is characterized by distant metastasis; however, spontaneous regression with a favorable prognosis has been clinically observed in the early 1970s. In addition, recent advancements in studies on the cellular and molecular characteristics of these cells revealed that NB cells have a similar morphology; however, they comprise heterogeneous cell groups. The mechanism underlying spontaneous regression is uncertain; however, cell differentiation and cellular apoptosis are considered to be related. Prognosis of advanced NB is still poor, and novel therapeutic trials such as molecular targeted therapies are urgently required; therefore, the association between "NB and apoptosis" is discussed herein.

\section{(1) Fenretinide induces apoptosis in NB cell lines}

We first studied fenretinide (FR)-induced apoptosis in KP-N-TK NB cells. After $48 \mathrm{~h}$ of incubation with FR, up to $70 \%$ of cells were TUNEL-positive and cleaved caspase-9, caspase-3, and PARP was observed at $24 \mathrm{~h}$, indicating the induction of apoptosis (Figure. 21AB). Intracellular reactive oxygen species (ROS) were generated upon 5-25 h of treatment with FR, and both JNK and p38 MAPK were activated in KP-N-TK cells (Figure. $22 \mathrm{AB})$

In the presence of antioxidant L-ascorbic acid (AA), TUNEL-positive cells were almost completely inhibited, and FR-induced cleaved caspase-9, caspase-3, and PARP were suppressed (Figure. 23AB). Furthermore, preincubation of AA suppressed FR-induced intracellular ROS accumulation in KP-NTK cells, and activation of JNK and p38 MAPR was remarkably suppressed (Figure. 24AB).

FR-induced intracellular accumulation of ROS and activation of JNK and p38 MAPK decreased in FR-resistant KP-NTK cell lines (data not shown).

Thus, our study was the first to report that FR induces sustained activation of JNK and p38 MAPK in a ROS-dependent manner in FR-sensitive NB cells (Figure. 25), but not in FR-resistant NB cells. Furthermore, our study was the first to show that the suppression of intracellular ROS production and the downstream JNK/p38 MAPK pathways are associated with FR resistance in NB cells [32]. At present, a phase I clinical trial to eradicate residual tumor cells in refractory NB patients is expected to assess this FR-induced therapy and hopefully cure this difficult-to-treat disease.

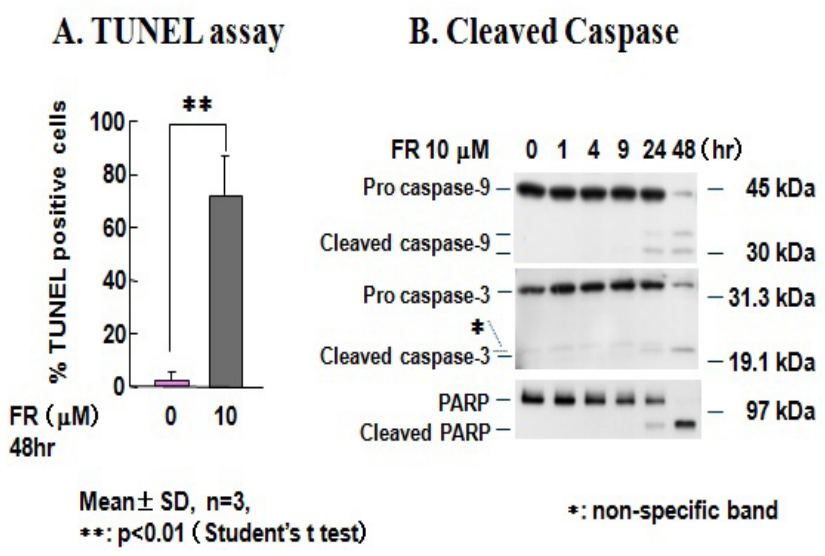

Figure. 21 Fenretinide-induced apoptosis in KP-N-TK NB cells and the appearance of cleaved caspase-9, caspase-3, and PARP. 


\section{A. Intracellular ROS B. Activated JNK \& p38 MAPK}

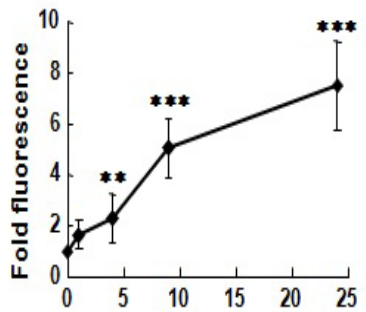

(hr)

Mean \pm SD $n=7$

**: $p<0.01, * * * ; p<0.001$

(compared with control, Student's t-test)

FR $10 \mu \mathrm{M} \quad 01492448(\mathrm{hr})$
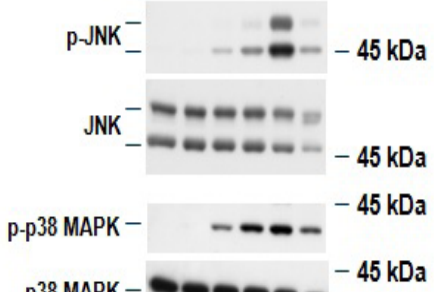

Figure. 22 Fenretinide-induced apoptosis, intracellular accumulation of reactive oxygen species, and activation of JNK and $\mathrm{p} 38$ MAPK in KP-N-TK NB cells.

\section{A. TUNEL assay}

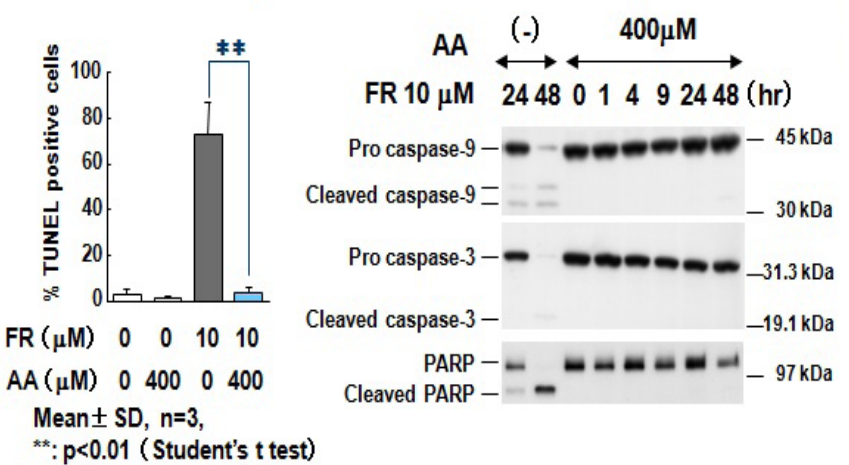

Figure. 23 Fenretinide-induced processing of caspase-9, caspase-3, and PARP was suppressed in the presence of antioxidant L-ascorbic acid.

\section{A. Intracellular ROS}

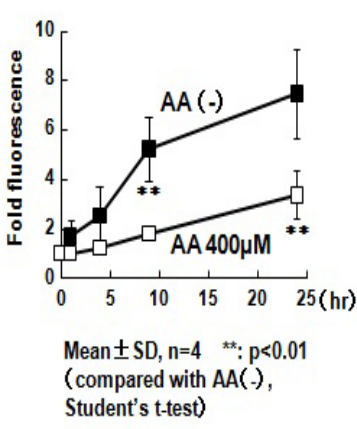

\section{B. Suppression of} JNK and P38 MAPR

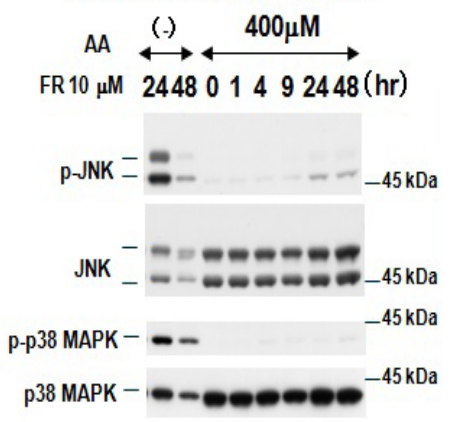

Figure. 24 Preincubation of KP-N-TK cells treated with ascorbic acid and fenretinide to suppress the accumulation of intracellular reactive oxygen species and suppression of JNK and p38 MAPR.

\section{FR}<smiles>[AlH]I</smiles>

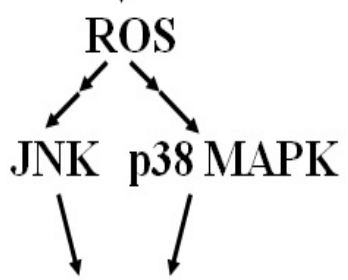

Caspase

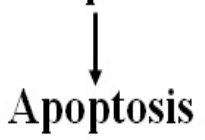

Figure. 25 Fenretinide-induced production of reactive oxygen species, JNK signaling, p38 MAPK signaling, and apoptosis in NB cells.

(2) Induction of apoptosis by an EGFR inhibitor in NB cell lines

Recently, some molecular-targeted anticancer drugs, which specifically inhibit protein tyrosine kinase receptors, have been developed and used clinically; gefitinib is the first antitumor agent used for non-small cell lung cancer and NB in vitro.

EGFR immunoreactivity was positive and confirmed via Western blotting analysis of $10 \mathrm{NB}$ tissues and KP-N-TK and KP-N-SIFA cell lines. Gefitinib inhibited EGFR phosphorylation and cell growth inhibition in vitro $\left(\mathrm{IC}_{50}\right.$ approximately $1.2 \mu \mathrm{M}$ ) (Figure. 26AB). A high gefitinib concentration [20-30] $\mu \mathrm{M}$ induced apoptosis in TUNEL-positive cells, and gefitinib induced caspase-3 and caspase-7 cleavage in KP-N-TK NB cells (Figure. 27AB) [33].

This was the first study to report that EGFR protein is expressed on the cell surface in NB tissue and NB cell lines and that molecular-targeted therapies may effective for NB. Our results indicate the feasibility of targeting EGFR as a novel treatment strategy for NB. 


\section{A. Immunoprecipitation}

B. Cell growth inhibition EGF $^{\text {gefitinib }}$
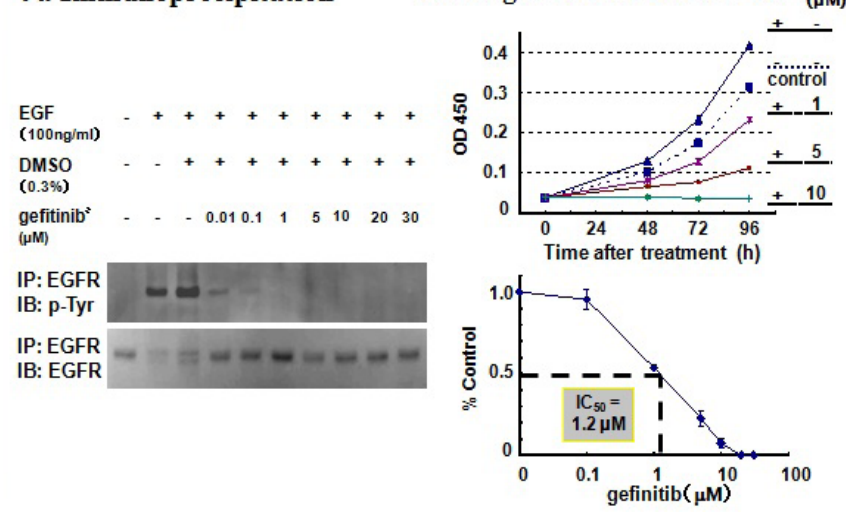

Figure. 26 Inhibition of EGFR phosphorylation and inhibition of cell growth by gefitinib in KP-N-TK NB cells.

\section{A. TUNEL assay}

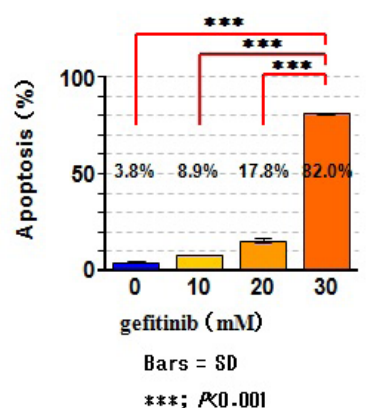

\section{B. Western blot}

gefitinib (mV)

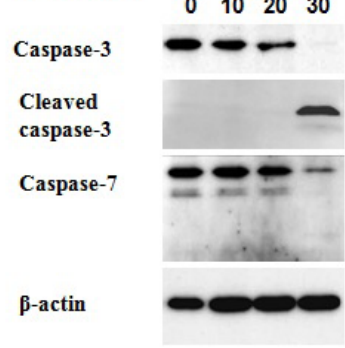

Figure. 27 Induction of apoptosis by gefitinib in KP-N-TK NB cells.

\section{Conclusion}

We had received frozen vials in Buffalo, NY, USA, and we established our cell bank in June 1982, in Kyoto, Japan, primarily to transfer our reference cell bank to generate monoclonal antibodies specific for NB cells. Tissues for sectioning were rapidly frozen in $\mathrm{OCT}$ compound and stored at $-80^{\circ} \mathrm{C}$ in our deep freezer. Serum samples before and after the diagnosis of $\mathrm{NB}$ have been stored at $-80^{\circ} \mathrm{C}$ in our deep freezer since August 1984. These frozen samples have been stored for basic and clinical in vitro and in vivo studies.

Regarding the cell bank, we established 16 cell lines from 12 NB patients, and have studied and characterized as though human NB tumors have been used ad-lib. Regarding the serum bank, simple, non-invasive, and accurate monitoring of serum MYCN DNA levels is warranted. In our second review, "Cellular and molecular characteristics of established childhood soft-tissue-sarcomas cell lines" will be discussed. These established cell lines are expected to provide novel insights into tumor biology.

\section{Acknowledgments}

We thank Drs. Jun Minowada, Tadashi Sawada, Yoshihiro Horii, Tamaki Hino-Saida and all members of our laboratory for their valuable guidance, discussion, and support. 


\section{References}

1) Sugimoto $T$, Gotoh T, Yagyu $S$, Kuroda $H$, Iehara $T$, et al. (2013) A MYCN-amplified cell line derived from a long-term event-free survivor among our sixteen established neuroblastoma cell lines. Cancer Lett 331: 115-121.

2) Imashuku S, Inui A, Nakamura T, Tanaka J, Miyake S (1973) Catecholamine metabolism in tissue culture cells of neuroblastoma. J Clin Endocrinol Metab 36: 931-936.

3) Biedler JL, Helson L, Spengler BA (1973) Morphology and growth, tumorigenicity, and cytogenetics of human neuroblastoma cells in continuous culture. Cancer Res 33: 2643-2652.

4) Thiele C (1999) Neuroblastoma. In Masters JRW, Palsson B eds. Human Cell Culture. Vol. 1, Norwell: Kluwer Academic Publishers 21-53.

5) Sugimoto T, Tatsumi E, Kemshead JT, Helson L, et al. (1984) Determination of cell surface membrane antigens common to both human neuroblastoma and leukemia-lymphoma cell lines by a panel of 38 monoclonal antibodies. J Natl Cancer Inst 73: 51-57.

6) Sugimoto T, Sawada T, Arakawa S, Matsumura T, Sakamoto I, et al. (1985) Possible differential diagnosis of neuroblastoma from rhabdomyosarcoma and Ewing's sarcoma by using a panel of monoclonal antibodies. Jpn J Cancer Res 76: 301-307.

7) Sugimoto T, Sawada T, Matsumura T, Kemshead JT, Horii Y, et al. (1988) Diagnosis of neuroblastoma metastasis in bone marrow with a panel of monoclonal antibodies. Med Pediatr Oncol 16: 190-196.

8) Sugimoto T, Sawada T, Matsumura T, Kemshead JT, Ishii T, et al. (1986) Identical expression of cell surface membrane antigens on 2 parents and 18 cloned cell lines derived from 2 different neuroblastoma metastases of the same patient. Cancer Res 46: 4765-4769.

9) Matsumura T, Sugimoto T, Sawada T, Tohru Saida, Kemshead JT (1988) Distinctive membrane phenotypes of neuroblastoma cells and fetal neuroblasts by a panel of monoclonal antibodies. Adv Neuroblastoma Res 2: 395-407.

10) Matsumura T, Sugimoto T, Sawada T, Amagai T, Negoro $S$, Kemshead JT (1987) Cell surface membrane antigen present on neuroblastoma cells but not fetal neuroblasts recognized by a monoclonal antibody (KP-NAC8). Cancer Res 47: 2924-2930.
11) Anderson DL (1997) Cellular and molecular biology of neural crest cell lineage determination. Trends Genet 13: 276-280.

12) Sugimoto T, Sawada T, Matsumura T, Horii Y, et al. (1987) Morphological differentiation of human neuroblastoma cell lines by a new synthetic polyprenoic acid (E5166). Cancer Res 7: 5433-5438

13) Sugimoto T, Sawada T, Matsumura T, Horii Y, et al. (1998) In: Evans AE, ed. Neuronal differentiation of human neuroblastoma cells by a novel synthetic polyprenoic acid. Advances in Neuroblastoma Res. New York: Alan R. Liss 337-351.

14) Sugimoto T, Horii Y, Hino T, Kemshead JT, et al. (1989) Differential susceptibility of HLA class II antigens induced by gamma-interferon in human neuroblastoma cell lines. Cancer Res 49: 1824-1828.

15) Sugimoto T, Kato T, Sawada T, Horii Y, Kemshead JT, et al. (1988) Schwannian cell differentiation of human neuroblastoma cell lines in vitro induced by bromodeoxyuridine. Cancer Res 48: 2531-2537.

16) Horii Y, Sugimoto T, Sawada T, Imanishi J, et al. (1989) Differential expression of $N$-myc and $c$-src proto-oncogenes during neuronal and schwannian differentiation of human neuroblastoma cells. Int J Cancer 43:305-309.

17) Sugimoto T, Ueyama H, Hosoi H, Inazawa J, Kato T, et al. (1991) Alpha-smooth-muscle actin and desmin expressions in human neuroblastoma cell lines. Int J Cancer 48: 277-283.

18) Matsumura T, Gotoh T, Sawada T, Sugimoto T (1998) A neuroblastoma cell line derived from a case detected through a mass screening system in Japan: A case report including the biologic and phenotypic characteristics of the cell line. Cancer 82: 14161417.

19) Sugimoto T, Mine H, Horii Y, Takahashi K, et al. (2000) Neuroblastoma cell lines showing smooth muscle cell phenotypes. Diagn Mol Pathol 9: 221-228.

20) Schwab M, Alitalo K, Klempnauer KH, Varmus HE, et al. (1983) Amplified DNA with limited homology to myc cellular oncogene is shared by human neuroblastoma cell lines and a neuroblastoma tumour. Nature 305: 245-248.

21) Seeger RG, Brodeur GM, Sather H, Dalton A, Siegel SE, et al. (1985) Association of multiple copies of the N-myc oncogene with rapid progression of neuroblastomas. N Engl J Med 313: 1111-1116. 
22) Hino $T$, Sugimoto $T$, Matsumura $T$, Horii $Y$, Inazawa J, et al. (1989) Diverse responses to retinoid in morphological differentiation, tumorigenesis and $\mathrm{N}-\mathrm{myc}$ expression in human neuroblastoma sublines. Int J Cancer 44: 286-291.

23) Gotoh T, Hosoi H, Iehara T, Kuwahara $Y$, Osone $S$, Tsuchiya $\mathrm{K}$, (2005) Prediction of MYCN amplification in neuroblastoma using serum DNA and real-time quantitative polymerase chain reaction. J Clin Oncol 23: 5205-5210.

24) Yagyu $S$, Iehara $T$, Tanaka $S$, Gotoh $T$, Misawa-Furihata $A$, Teramukai S, et al. (2016) Serum-based quantification of MYCN gene amplification in young patients with neuroblastoma: Potential utility as a surrogate biomarker for neuroblastoma. PLoS One 11: e0161039.

25) Nakagawara A, Arima-Nakagawara M, Scavarda NJ, Azar CG, et al. (1993) Association between high levels of expression of the TRK gene and favorable outcome in human neuroblastoma. N Engl J Med 328: 847-854.

26) Nakagawara A, Azar CG, Scavarda NJ, Brodeur GM (1994) Expression and function of TRK-B and BDNF in human neuroblastomas. Mol Cell Biol 14:759-67.

27) Sugimoto T, Kuroda H, Horii $Y$, Moritake H, Tanaka T, et al. (2001) Signal transduction pathways through TRK-A and TRK-B receptors in human neuroblastoma cells. Jpn J Cancer Res 92: 152-160.

28) Horii Y, Kuroda H, Sugimoto T (1998) Frequent detection of TrkA expression in human neuroblastoma cell lines. Acta Paediatrica Jap 40: 644-646.

29) Kuroda H, Sugimoto T, Horii Y, Sawada T (2001) Signaling pathway of ciliary neurotrophic factor in human neuroblastoma cell lines. Med Pediatr Oncol 36: 118-121.

30) Kuroda H, Sugimoto T, Ueda K, Tsuchida S, et al. (1991) Different drug sensitivity in two neuroblastoma cell lines established from the same patient before and after chemotherapy. Int J Cancer 47: 732-737.

31) Moritake H, Horii Y, Kuroda H, Sugimoto T (2001) Analysis of PTEN/MMAC1 alteration in neuroblastoma. Cancer Genet Cytogenet 125: 151-155.

32) Osone S, Hosoi H, Kuwahara Y, Matsumoto Y, et al. (2004) Fenretinide induces sustained activation of JNK/p38 MAPK and apoptosis in a reactive oxygen species-dependent manner in neuroblastoma cells. Int J Cancer. 112: 219-224.

33) Tamura S, Hosoi H, Kuwahara Y, Kikuchi K, Otabe O, et al. (2007) Induction of apoptosis by an inhibitor of EGFR in neuroblastoma cells. Biochem Biophys Res Commun 358: 226-232.

\section{Disclaimer}

* The Japanese review entitled "Contribution of our establishedpediatric malignant cell lines to clinical and basic medical science" was published in Journal of Kyoto Prefectural University of Medicine, 117 ([3)], 135--165, 2008 in Japanese, which was to totally completely revised, and divided into two English reviews.

Submit your manuscript to a JScholar journal and benefit from:

- Convenient online submission

I Rigorous peer review

- Immediate publication on acceptance

- Open access: articles freely available online

9 High visibility within the field

- Better discount for your subsequent articles

Submit your manuscript at http://www.jscholaronline.org/submit-manuscript.php 